\title{
The Mathematization Process as Object-oriented Actions of a Modelling Activity System
}

\section{O Processo de Matematização como Ações Orientadas ao Objeto de um Sistema Atividade de Modelagem}

\author{
Jussara de Loiola Araújo* \\ ORCID iD 0000-0002-9156-2417 \\ Fernando Henrique de Lima** \\ ORCID iD 0000-0002-5745-5255
}

\begin{abstract}
In this paper, we describe and characterize the mathematization process that happened in an open mathematical modelling project, in which all decisions, from the choice of a real-world problem to its solution, were taken collectively by a group of students and researchers. The study was developed according to a qualitative methodological approach. Based on modelling in mathematics education studies and on the Cultural-Historical Activity Theory (CHAT), we could interpret the mathematization process as a set of actions oriented to the activity system object, and the modelling project objective as the activity object itself. We concluded that the mathematization process, permeated by tensions, took place concurrently with the delimitation of the modelling project objective, which caused a series of advances and setbacks in the subjects' actions.
\end{abstract}

Keywords: Cultural-Historical Activity Theory. Mathematics Education. Mathematical Modelling. Mathematization. Modelling Project Objective.

\section{Resumo}

Neste artigo, descrevemos e caracterizamos o processo de matematização que ocorreu em um projeto de modelagem matemática aberto, no qual todas as decisões, desde a escolha do problema do mundo real até sua solução, foram tomadas coletivamente por um grupo de estudantes e pesquisadoras. A pesquisa foi desenvolvida segundo uma abordagem metodológica qualitativa. Baseados em estudos de modelagem na educação matemática e na Teoria Histórico-Cultural da Atividade, pudemos interpretar o processo de matematização como um conjunto de ações orientadas ao objeto do sistema atividade e o objetivo do projeto de modelagem como o próprio objeto da atividade. Concluímos que o processo de matematização, permeado por tensões, ocorreu concomitantemente com a delimitação do objetivo do projeto de modelagem, o que provocou uma série de avanços e retrocessos nas ações dos sujeitos.

Palavras-chave: Teoria Histórico-Cultural da Atividade. Educação Matemática. Modelagem Matemática. Matematização. Objetivo de Projeto de Modelagem.

\footnotetext{
* Doctor in Mathematics Education, Universidade Estadual Paulista (Unesp - Rio Claro). Professor at Mathematics Department and Graduate Program in Education, Universidade Federal de Minas Gerais (UFMG), Belo Horizonte, Minas Gerais, Brasil. Address for correspondence: Departamento de Matemática, Instituto de Ciências Exatas, Universidade Federal de Minas Gerais, Av. Presidente Antônio Carlos, 6627, Belo Horizonte, Minas Gerais, Brasil, CEP: 31.270-901. E-mail: jussara@ mat.ufmg.br.

${ }^{* *}$ Master in Education, Universidade Federal de Minas Gerais (UFMG). Addres for correspondence: Faculdade de Educação, Universidade Federal de Minas Gerais, Av. Presidente Antônio Carlos, 6627, Belo Horizonte, Minas Gerais, Brasil, CEP: 31.270-901. E-mail: fernandolima@ufmg.br.
} 


\section{Introduction}

Mathematical modelling in mathematics education refers to the development of tasks in a classroom environment in which students are involved in the search for solutions to real-world problems through the use of mathematical knowledge. Although very general, this common idea mentions a moment that may be of special interest to mathematics education: the process of insertion or use of mathematical elements (techniques, concepts, procedures, theorems, etc.) in a real-world problem that, at first, did not include such elements. This process is known as mathematization (BLUM; NISS, 1991; NISS et al., 2007).

Many authors propose modelling cycles or phases (e.g. ALMEIDA; SILVA; VERTUAN, 2012; BLUM; LEIß, 2007), which are structures that guide students through steps that must be followed during mathematical modelling. One of these steps is the mathematization and, because of the key idea of modelling - solving real-world problems through mathematical knowledge - we believe that characterizing this step in detail is important to understand mathematical modelling as a whole.

In this paper, our objective is to describe and characterize the mathematization process that happened in an open mathematical modelling project, in which all decisions, from the choice of a real-world problem to its solution, were taken collectively by a group of students and researchers. We begin by presenting a discussion about mathematization in the modelling field literature in mathematics education.

\section{The mathematization process in mathematical modelling}

While developing modelling projects, students are asked to conduct investigations having as a starting point a real-world problem. During this process, students create hypotheses and use mathematics to solve the problem posed, performing mathematization (BLUM; NISS, 1991; NISS et al., 2007).

Niss et al. (2007, p. 9) claim that during mathematization, "the relevant objects, data, relations, conditions, and assumptions from the extra-mathematical domain are then translated into mathematics, resulting in a mathematical model through which to address the identified problem". Similarly, Stillman et al. (2015, p. 94-95) state that mathematization involves a translation from the real situation into the mathematical domain and that "the mathematical model made of the situation, mathematical questions posed and mathematical artefacts (e.g., graphs and tables) used in solving the mathematical model" constitute this mathematical 
domain.

From literature, we highlight some works that aim to comprehend the participation of students during modelling, more specifically during mathematization. Schaap et al. (2011) analyzed the occurrence of obstacles, as well as the students' steps to overcome those, while developing modelling activities. Their focus is on the mathematization process and the authors believe, as we do, that mathematization and modelling construction do not happen linearly. In the same way, Maaß (2007) describes a series of slips and mistakes the students make during the process of constructing mathematical models. The author adds that it is common for students to accumulate a great amount of information during the development of such activities and eventually end up getting lost in their way with the procedures; and that "these failures show that it is obviously necessary to have an overall view and to work purposefully. A sense of direction is necessary" (MAAß, 2007, p. 74).

Having as theoretical reference the Realistic Mathematic Education, Carreira and Baoia (2011) present a project with nine-graders in which a mathematical modelling task was proposed. The authors highlight the mathematization process, stating that this stage "includes both horizontal and vertical developments" (p. 214). Based on Hans Freudenthal's ideas, the authors state that "horizontal mathematization involves the passage from the world of life into the world of symbols and vertical mathematization means moving within the world of symbols" (p. 214). It was observed that experiments performed with students during the modelling activity helped them in the mathematization process and, "although experimentation may seem to keep some students at the level of horizontal mathematization, the modelling process final stages reveal that it is actually promoting a deeper conceptual development" (p. 219).

Sol et al. (2011) describe sixteen hypothetical modelling actions and part of them is directly connected to the mathematization process. In the end, the authors describe the routes the students used to solve their activities through the actions each of them took to solve the problem. As Schaap et al. (2011), this study also "shows that the model does not have a linear continuity" (SOL et al., 2011, p. 237). And corroborating the results of Maa $\beta$ (2007), also in this study the students "are not aware of the modelling process as a global mathematical process" (SOL et al., 2011, p. 237).

These studies suggest that it would be interesting to find a framework that helps understand these not linear and, perhaps, complex paths followed by students while performing mathematization, keeping the whole process in mind while dealing with details of the modelling project. We believe that the Cultural-Historical Activity Theory (CHAT) can be this framework, due to some of its concepts and structures, as we present in the next section. 
The studies of Wake $(2014,2016)$ approach CHAT and modelling in mathematics education. Wake (2014) uses CHAT as the framework to analyze the relationship between academic mathematics and mathematics in the workplace. However, his intention is "to inform how we might develop a mathematics curriculum for compulsory schooling from research into workplace activity" (p. 272). Modelling would be part of this curriculum. Wake (2016), by his turn, is interested in the students' transition through college and into university, concluding that by means of different mediation, "students experience modelling and applications as mathematical practices very differently in each [context]" (p. 172).

In these studies, CHAT is the framework used to analyze lager contexts (school vs. workplace or different school levels) and, in some of them, modelling is part of the contexts. So, modelling is not the focus of analysis. In our study, however, we intend to use CHAT to analyze what happens inside modelling projects, by focusing on the mathematization process. We believe that this approach can lead to new insights on the students' actions in modelling projects.

Considering smaller contexts, Almeida and Brito (2005) focus their study on sense attribution and meaning construction in mathematical modelling activities and base themselves in the motives and necessities of the students, two concepts of CHAT. By their turn, PosadaBalvin and Borba (2019) are interested in the teaching of algebraic concepts in modelling pedagogical projects and CHAT was used to organize the empirical material. By studying the interactions of two teachers, during an online education course on modelling and applications, Galleguillos and Borba (2017) focused on tensions - based on CHAT - in the process of posing and solving a modelling problem. The authors concluded that modelling made tensions visible and "allowed teachers to move from a conflict to the formulation of an open problem, and from a dilemma to the construction of a model and a pedagogic strategy" (p. 129). Although carried out in smaller modelling contexts in mathematics education, none of these studies approaches the mathematization process.

Finally, Stilmann et al. (2015) present a framework, supported by theoretical arguments and empirical evidence, which aims to scaffold inexperienced students in modelling activities. Like our study, they are based on an open modelling activity, which theme and developments are chosen by the students. Stillman et al. (2015, p. 103, our emphasis) conclude that the framework highlights "the effectiveness of discussion in leading to model construction through appropriate mathematization processes". The framework presented by the authors is a set of questions that, in our view, directs a priori the students' actions during modelling activities. And even though that might lead to "appropriate mathematization processes", the framework might 
not allow the students' own actions to be highlighted.

Regardless of the appropriateness or not of the mathematization process, we have as objective to describe and characterize this process in an open modelling project, in which there is no scaffolding, previously planned, to the students. In order to do so, we base ourselves in a framework - Cultural-Historical Activity Theory - that let us track the paths followed by students and researchers, presented in the next section.

\section{Cultural-Historical Activity Theory}

The Cultural-Historical Activity Theory (CHAT) evolved from the cultural-historical school of thought in Soviet psychology, which most prominent name is Lev Vygotsky, and has philosophical roots in Karl Marx's work. The dialectical mediation between subject and object, through artefacts (tools and signs), is the core idea in the theory developed by Vygotsky. Alexei Leont'ev developed Vygotsky's studies and, after three generations of research (ENGESTRÖM, 2001), CHAT has been evolving as a theoretical-methodological framework. In this paper, we base ourselves on the third generation of CHAT and understand that "from an activitytheoretical perspective, human life is fundamentally rooted in participation in human activities that are oriented toward objects" (SANNINO et al., 2009, p. 2).

The subjects of an activity system are the individuals whose actions are taken as reference for analysis; meanwhile its object is "the "raw material" or "problem space" at which the activity is directed" (ENGESTRÖM; SANNINO, 2010, p. 6). Activity systems are realized or concretized by means of actions. Here, we consider the actions of students and researchers - subjects of an activity system - in the modelling project mathematization process. Doing that, we will be able to describe some characteristics of the activity system in which students and researchers are engaged, including its object. "Being a horizon, the object is never fully reached or conquered" (ENGESTRÖM, 1999, p. 381), it is a "moving target" (ENGESTRÖM, 2001, p. 136) and so, we understand that the object is not completely clear at first. Thus, we will try to unveil the activity system object during the data analysis process. Subjects, object and other elements of an activity system and relationships among them were organized on a triangular representation, presented in Figure 1. 


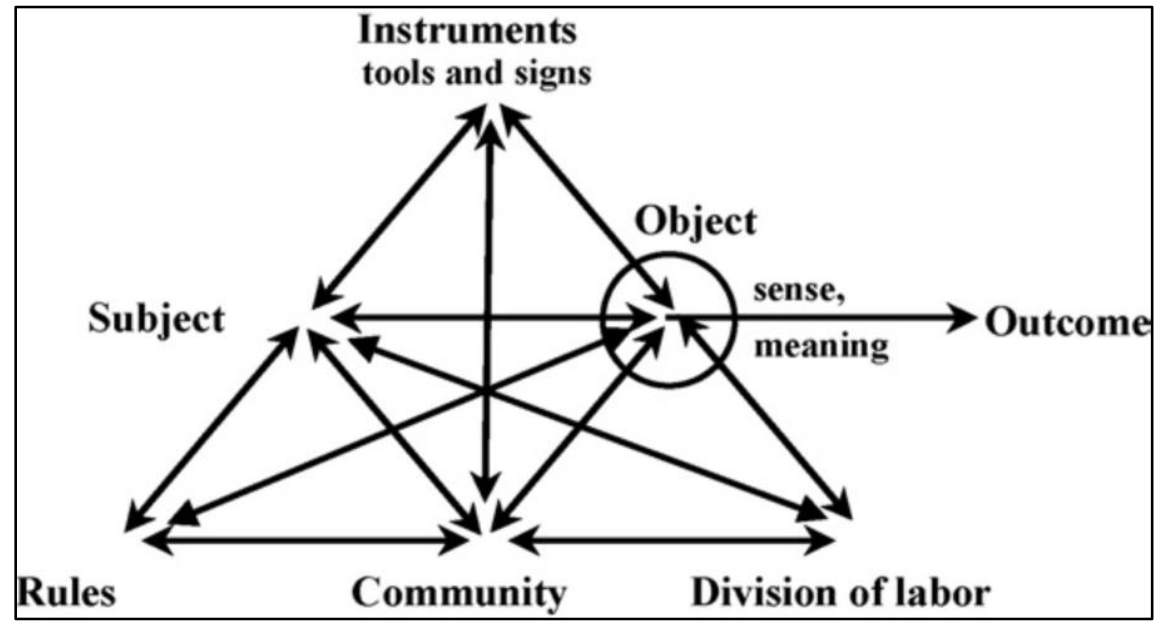

Figure 1: Structure of a human activity system

Source: Engeström and Sannino (2010, p. 6)

In this diagram, each triangle represents the dialectical mediation between two elements (located at the vertices of the triangle) realized by the element located at the third vertex. For instance, the upper triangle represents the dialectical mediation between subjects and object by tools and signs, the key idea by Vygotsky. Concurrently, there is another dialectical mediation between subjects and object realized by community. The relation between subjects and community is mediated by rules. Finally, the relation between community and object is mediated by division of labor established in the community, which is described as a horizontal division of tasks and a vertical division of power.

As a result of the activity system, the activity object is transformed into an outcome. However, this transformation does not happen in a direct way. According to Engeström (2001, p. 134), “object-oriented actions are always, explicitly or implicitly, characterized by ambiguity, surprise, interpretation, sense making, and potential for change". The circle around the object, in Figure 1, aims to highlight its complexity, ambiguity, and invitation to interpretation.

\footnotetext{
The object is an invitation to interpretation, personal sense making and societal transformation. One needs to distinguish between the generalized object of the historically evolving activity system and the specific object as it appears to a particular subject, at a given moment, in a given action. The generalized object is connected to societal meaning, the specific object is connected to personal sense (ENGESTRÖM; SANNINO, 2010, p. 6).
}

The dual character of the object is closely related to the contradictions of the activity system. According to Engeström (2001, p. 137), "contradictions are historically accumulating structural tensions within and between activity systems," and are sources of change and transformations. The author clarifies that contradictions may happen when activity systems, which are open, allow for the insertion of new elements, which generates tension with the preexisting ones. Tensions also emerge when two or more subjects have different perspectives 
regarding the actions that they are performing (DAVID; TOMAZ, 2015).

The previous paragraph describes relationships among three of five CHAT principles ${ }^{1}$ (ENGESTRÖM, 2001): the historicity, the central role of contradictions and "the possibility of expansive transformations in activity systems" (p. 137), by facing contradictions. They will be discussed in the next section, supporting the description of the methodological aspects of the research.

\section{Methodological aspects}

CHAT brings history in its own name and "is one that develops as an integral part of the historical turmoil in which activity theorists live" (SANNINO et al. 2009, p. 11). The principle of historicity states that activity systems are shaped and transformed for long periods of time (ENGESTRÖM, 2001) and so, we must look at their problems in the context of their own history. However, in our study, we are dealing with a shorter period of time if compared, for example, with the long-term researches developed by the scholars of the third CHAT generation. To get around this situation, we rely on studies of David et al. (2014) and David and Tomaz (2015), carried out in mathematics classrooms. The authors use the idea of potentially expansive miniature cycles (ENGESTRÖM, 1999; ENGESTRÖM; SANNINO, 2010) as an analytical tool. The strategy is to analyze classrooms events deeply at the micro level, to look for small changes that could be interpreted as potentially expansive. By doing that, it is possible to capture

the historicity of the classroom activity and the cultural embodiment of the activity systems, identifying moments of possibly small changes and transformations in the components of the ongoing activity, and illuminating tensions and contradictions between different cultural perspectives present in the classroom (DAVID et al., 2014, p. 97).

In summary, we intend to consider the historicity and contradictions - understood as accumulating tensions - as possibilities to expansive transformations, but in the smaller scale of the miniature cycles. For that, it is necessary to describe the research context, which includes the development of the modelling project, to contemplate part of the historicity of the activity system.

\footnotetext{
${ }^{1}$ The others two principles are the activity system taken as unit of analysis and the multi-voicedness of activity systems.
} 


\subsection{The mathematical modelling project: the research context}

The empirical part of the research was developed by three researchers: Jussara Araújo (researcher in charge), Maria and Aline (assistant researchers). Throughout the data analysis process, a fourth assistant researcher, Fernando Lima, joined the group. Five students, from three different courses within the Exact Sciences area at the Universidade Federal de Minas Gerais (UFMG), accepted the invitation to take part in the research, outside the context of formal courses at the university: Alberto, from the Systems Engineering course; Pedro and Rafael, from the Physics course; Natália and Débora ${ }^{2}$, from the Mathematics course. Previously, all of them had been enrolled in disciplines under the responsibility of Prof. Jussara Araújo and, somehow, they were curious to learn about research development at the university.

The group composed by the three researchers and the five students was responsible for the development of the mathematical modelling project, over nine meetings on Saturday afternoons, from October, 2012, to June, 2013. The project was developed in a computer lab at the Instituto de Ciências Exatas (ICEx) at UFMG. The students were asked to report the project development in a shared document - which both researchers and students had access to - stored by the application pack Google Drive ${ }^{3}$. This way, the participation in the project could happen in person or virtually, in the virtual space created for the group.

The development of modelling projects is not common in the routine of classes at ICEx and a special pedagogical practice was created to be the research context, establishing a pedagogical practice|research dialectic (ARAÚJO, 2019). According to Antonius et al. (2007), there are different ways to organize modelling activities in school, and one of them is the development of projects. Projects, according to the authors, approach broader problems that might extend for months. That was the format we chose, and therefore we use the term "modelling project". Another characteristic of the modelling project is the fact that the five students chose the real-world situation to be investigated. This characteristic is quite common in modelling in mathematical education in Brazil (ARAÚJO, 2010).

The students were invited to propose a theme and, from it, elaborate a problem or a more specific objective to be investigated in the modelling project. They were supposed to plan the steps to get information, organize it, and use mathematical knowledge/tools to reach the project objective. Since students were not familiarized with modelling projects, the researchers were ready to step in in case of tensions to guarantee the flow and conclusion of the project. This was

\footnotetext{
2 The names of the students and of the researchers, who are not authors of this paper, are fictitious.

3 'Google Drive' is a file storage and synchronization service, presented by Google' (GOOGLE DRIVE, 2015).
} 
an ethical attitude regarding the students' development in this pedagogical practice, since a consistent education in modelling was a way to benefit the students who were voluntarily participating in the research. Simultaneously, aligned with CHAT, our study "involves the researcher throughout the course of the development, stagnation, or regression of the activities under scrutiny, as well as in the activities of the research subjects" (SANNINO et al. 2009, p. $3)$.

The theme of the modelling project chosen by the students was the purchase of property (real estate). Although it was not a previous problem for anyone of the students, they agreed that purchasing a property could be a problem faced by anyone at any given moment in life. So, they decided that this theme would be a common problem among them. This theme was, then, the starting point for the actions performed by the students and researchers - the subjects of the activity system -, during the modelling project. The object and the outcome of the activity system will be unveiled during the analysis process, as well as tools and signs. ${ }^{4}$

\subsection{Research procedures}

The nature of the research was qualitative. For the production of data, we did participant observations (ADLER; ADLER, 1994), once the researchers acted and intervened during the modelling project created for the research development. The observations were registered through field notes and filming.

We organized the data in three miniature cycles, for their description and analysis. The group elaborated three versions of the mathematical model and each of these versions was the benchmark we chose to end each of the three miniature cycles, since "the cycle ends when a new pattern of activity has become consolidated and relatively stable" (ENGESTRÖM; SANNINO, 2010, p. 11). It is important to highlight that these three miniature cycles are part of a longer activity system in which the group composed of researchers and students were involved. We are only interested in the period of time that the mathematization process took place in the modelling project. Therefore, the analysis that we will do, which includes the search for the activity system object, concerns only that part of the history of the activity system. In other words, the activity system elements and the relationships among them can be different before and after the period of time we choose to analyze. This would be completely natural, since activity systems are constantly changing (ENGESTRÖM, 1999).

\footnotetext{
${ }^{4}$ Because of limitation of space, we will focus our analysis just in these elements of the activity system.
} 
Analysis happens concurrently to the data description, through the selection of excerpts from the field notes, from the project development reporting made by students in the shared document, from e-mails, and from footage transcriptions, in tune with the theoretical framework already presented.

\section{The mathematization process in an open mathematical modelling project}

At the beginning, just the modelling project theme - the purchase of property (real estate) - was clear to the group. They did not have a clearly defined objective for the project. Thus, in the first miniature cycle described next, we find the students and researchers trying to define the modelling project objective.

\subsection{First miniature cycle: Trying to define the modelling project objective}

The data used to describe this miniature cycle was taken from the field notes made in the second group meeting. In this meeting, the present subjects were Alberto, Pedro and Rafael, and the researchers Maria, Aline, and Jussara.

Initially, the group discussed what can influence the definition of property value and what a person considers when choosing a property to purchase. Based on their own experiences, the subjects made a list of the factors

which people tend to consider when purchasing property: the property value, how much the person will or can invest, the property location, the number of rooms, etc.

(Field notes).

In order to clarify these factors, the group decided to elaborate a questionnaire (see Appendix) to be applied to the biggest number of people possible, handwritten or via social media networks. In the first part of the questionnaire, personal data were required of those answering it. In the second part, the group created a list with nineteen factors that could be considered when purchasing property, and the interviewees should classify each factor in terms of importance on a scale from 0 to 10: 0 meaning no importance and 10 meaning extreme importance, or choose the Not Applicable (N/A) option.

This initial discussion suggests a first version of the modelling project objective: to detect

factors that influence the choice of property, by the buyer.

(Field notes). 
After deciding for the application of the questionnaire, and aware that the group was performing modelling, Alberto proposed a plan for the construction of the mathematical model:

each factor will carry a weight, according to the questionnaire results. Moreover, each factor we are able to model mathematically will have a model. Then, we can calculate a weighted mean.

(Field notes).

Since Alberto did not express his proposal mathematically, to advance the discussion, Jussara tried to write his plan in mathematical terms, making a draft of this first possibility of a model. However, Jussara clarified that she did not know what this model could measure:

$$
\text { "Model": } \frac{\sum_{i=1}^{n} \text { Weight }_{i} \cdot \text { Model }_{i}}{\sum_{i=1}^{n} \text { Weight }_{i}}
$$

The actions realized by the activity system subjects in the first miniature cycle were:

- discussions about the theme of the modelling project;

- creation of a list of factors which might be considered when purchasing property;

- elaboration of a questionnaire.

Because of these actions, the activity system subjects elaborated the first version of the modelling project objective: detecting factors that can influence the choice of property.

There was a movement in the subjects' actions towards the modelling project objective, which during the first miniature cycle was not well established. Maaß (2007) states that it is crucial to have a sense of direction in modelling activities, which was not the case for the project described here. The object of an activity system is also obscure at first (ENGESTRÖM, 1999; FOOT, 2002). The possible objective, which was being delimited from the project theme, was then, "the "raw material" or "problem space" at which the activity is directed" (ENGESTRÖM; SANNINO, 2010, p. 6). Thus, we can consider the first version of the project objective as an initial attempt at unveiling the activity system objective.

The mediation between subjects and object was done through language (including mathematical language) and tools available at the computer lab. The subjects' actions led to the construction of Model 1. Similar to the fact that the mathematization process leads to the construction of the mathematical model (NISS et al., 2007), the object-oriented actions turn the object into the activity system outcome (ENGESTRÖM, 2001). Thus, we can consider Model 1 as the first version of the activity system outcome.

In this miniature cycle, Alberto began the insertion of mathematical elements into the real-world situation being analyzed by the group. He talked about weight, mathematically modelling, and weighted mean, which are terms used in mathematics. This signals the beginning of the mathematization process. However, he did not express his idea through mathematical 
formulas, which was done by the researcher Jussara. As described in section 4, this intervention was predicted in the research plan. Besides, it is quite common for students to have difficulties with the mathematization process in modelling activities (SCHAAP et al., 2011).

The first version of the model (Model 1) was only dealt with again much later, after the application of the questionnaire to a group of 163 people. Before that, with the data collected from the questionnaire already in hand, the group moved back in the mathematization process, as we describe next, in the second miniature cycle.

\subsection{Second miniature cycle: Working with the data from the questionnaire application}

The data used to describe this miniature cycle are excerpts transcribed from the video of the eighth group meeting. In this meeting, the subjects Débora, Natália, and Pedro, and the researchers Maria, Aline, and Jussara were present. As the meetings happened on Saturday afternoons, some students were occasionally absent. However, this fact did not hinder the project, since the whole group was also virtually available during project development, through use of a shared document in Google Drive.

The group intended to analyze the data collected from the questionnaire application. They did not return to the first version of the project objective, and, at the beginning, they were merely reading the answers to the questionnaire, without a clearly defined purpose.

At a given moment, Pedro observed that item ${ }^{5} 10$ in the questionnaire, which concerned the proximity to hospitals factor, had answers similar to the ones given to item 8 , which concerned the proximity to shopping centers factor. Thus, the group started to create a strategy based on the similarity of answers given to different items, as described in the excerpt below:

Pedro: But hospital is similar to shopping center, right?

Aline: Oh no!

Jussara: But if we classified these ans... questions according to the similarity of answers?

Pedro: Similarity of the answers, yes!

Aline: Hmmm!? Such as...

Jussara: It is like you just said it. Hospital is kind of similar to shopping center. Let's organize them into these groups.

Maria: It is like, in a way, they have the same degree of relevance, these two things.

Pedro: It is somewhere [place] I go to, sporadically.

Jussara: So, look... hospital and shopping center are similar. The interest in a property is similar to industry?

Aline: So, what stands out between 0 and 3 could be in a group, between 4 and 6 in another group...?

$\left(\right.$ Video transcript $\left.{ }^{6}\right)$.

\footnotetext{
${ }^{5}$ In the questionnaire (Appendix), the word item is used to refer to the factors that might influence when purchasing property. In the videos, the subjects used the words item, factor, and question with the same meaning.

${ }^{6}$ All the videos transcriptions in the paper are from the eighth meeting.
} 
In this excerpt, Pedro starts to compare and look for similarities among answers. The idea was followed by the group, which started classifying the items according to similarities among the answers. The researcher Aline suggested that items were grouped according to the highest frequency of answers between 0 and 3, 4 and 6, etc. (See Appendix). Refining the idea, they started considering three groups of answers: those that spanned from N/A to value 2; the ones that spanned from values 3 to 6 ; and the ones that spanned from values 7 to 10 . And Aline continued:

Aline: My first step was like this: question 1, and then we would put here in the 1, 2, 3. (Video transcript).

Aline's idea was to classify each item according to the frequency of answers given to each of the three value groups. Maria understood Aline's idea and explained it to the other members in terms of weighting of relevance:

Maria: It is as if she [Aline] was giving weight. For instance, we were putting weight 1, weight 2 , and weight 3, to question 1... What carried the most weight was group 3, then the next weight was group 2, and, lastly, this one we are calling group 1. She wants to give weight to each one... it is because she does not want to disregard the other factors. It is like she said: 'there is relevance in these other factors, but less relevance'.

(Video transcript).

The participants, then, started working together on the answers given to the questionnaire, aiming to classify each item. With time, they adopted a new way to name each group of items that were similar, according to the same pattern. To exemplify, we present, in Table 1, the classification of the first five items:

Table 1: Classification of the first five items in the questionnaire

\begin{tabular}{ccccc}
\hline Item & $\begin{array}{c}\text { Frequency of NA } \\
\text { to 2 answers } \\
\text { (group 1) }\end{array}$ & $\begin{array}{c}\text { Frequency of 3 to 6 } \\
\text { answers } \\
\text { (group 2) }\end{array}$ & $\begin{array}{c}\text { Frequency of 7 to } \\
\text { 10 answers } \\
\text { (group 3) }\end{array}$ & Pattern of the item \\
\hline 1 & 12 & 42 & 109 & $1-2-3$ \\
2 & 25 & 87 & 51 & $1-3-2$ \\
3 & 14 & 36 & 113 & $1-2-3$ \\
4 & 10 & 26 & 127 & $1-2-3$ \\
5 & 34 & 66 & 63 & $1-3-2$ \\
\hline
\end{tabular}

Source: prepared by the authors

The actions realized by the subjects in the second miniature cycle were:

- reading the questionnaire answers, without a clearly defined objective;

- comparing the answers to find similarities among them;

- creating a strategy to analyze the answers, aiming to compare them;

- analyzing the answers, using the strategy;

- classifying the similar items in groups following the same pattern;

- naming the patterns. 
The modelling project objective remained undefined during the second miniature cycle, since the activity system subjects did not mention it, nor re-elaborated it. However, considering the actions of the group were oriented towards a classification of factors that might be taken into account when purchasing property, we describe, then, a refinement of the activity system object: classifying the factors that might influence choosing the property. The subjects' actions, in the second miniature cycle, originated Model 2, illustrated in Table 1. This is, then, the second version of the activity system outcome.

There was a long hiatus separating the first miniature cycle from the second one, and Model 1, proposed by Alberto and Jussara, was not mentioned here. In the second miniature cycle, the mathematical elements were inserted by Pedro - comparing, finding similarities, and classifying into patterns - which are typical actions in mathematics. In our interpretation, there was a new beginning to the mathematization process and it was expressed in numerical terms by Aline, originating Model 2. As in the first miniature cycle, a student described mathematization in colloquial language and a researcher translated it into mathematical language. This strategy and the model constructed were questioned by Pedro, which, once more, changed the course of the mathematization process, as we describe next in the third miniature cycle.

\subsection{Third miniature cycle: Refining the model}

The data used to describe this miniature cycle are excerpts transcribed from the video of the eighth group meeting (the same of the previous miniature cycle, with the same participants) and excerpts from an e-mail exchange, which happened immediately after this meeting. While the group worked with the data, Pedro posed a question:

Maria: [...] We are all going to work together, isn't that right? [pause to analyze questions] Look... well, this is more visible, I believe, right? The last group, the one we are calling group 3, it has more weight. [...] Are we doing it this way?

Aline: Yep.

Pedro: No... well... But what about the weight of each one of them inside it? Aren't we... disregarding it?

Aline: How so?

Pedro: The weight of... For example, 10 has a bigger weight than 9, did you consider that...? Aline: No. We are considering the interval.

(Video transcript).

After a few minutes, Pedro found a concrete situation which showed it was necessary to refine the classification the group was planning:

Pedro: The [question] 5 tied... [the groups] 2 and 3 tied. 
Maria: Seriously?

Pedro: Yes! It will need $a 2$ and a half there [laughs]

Aline: Then we can adopt new criteria.

Pedro: That is what I'm saying: give a little weight to each one inside it.

(Video transcript).

At the same time, Aline expressed the need to define the modelling project objective.

Aline: Hey guys, hold it! We will analyze it... To me, we should have a...

Jussara: A criteria.

Aline: ...yes!

Jussara: An objective [Pedro and Aline agree].

Aline: Or else, we will generate many... Not that it is unproductive. It is very productive but... Jussara: It is not objective, is it?

Aline: Nope. What do we want?

(Video transcript).

Pedro and Aline's questions can be understood as tensions (ENGESTRÖM; SANNINO,

2010) in the group's activity system, caused by the subjects' different perspectives.

Contradictions, which are structural tensions historically accumulated, may aggravate and provoke doubts in the subjects, leading to changes in the activity (ENGESTRÖM, 2001). Aware of this, Jussara proposed some routes, trying to deal with these tensions:

Jussara: If we did that for each question, we would have a similar process and more detailed information. I don't know if that makes sense to you. For example, what are the questions which preference was answer 0? What are the questions whose preference was answer 1?

Débora: Because maybe a question is in a block [...] The same question, which is in block, for instance, 1-2-3, the question that had more answers might not be the one in block $3 . .$.

Jussara: I have here a model that Alberto brought about, which is to give weight to each of the... [questions] which is what we are doing... to each one of the... Here [points to the field notes from the second group meeting] each factor will have a weight according to the result of the questionnaire.

[…]

Jussara: We have to formalize our objective. Let's take Alberto's criteria?

(Video transcript).

With this proposal, Jussara tried to connect the two different routes to mathematization the group had reached, respectively, in the first and second miniature cycle. This kind of researcher intervention is expected in studies based on CHAT and, in our case, it was needed for the group to take advantage of the tensions. The group then proceeded to re-elaborate Model 1, from the strategies and classification used to build Model 2 (Table 1):

Jussara: Now, each question, we will associate to a weight...

Aline: A weight. The questions that had the regularity 1-2-3, that means they were the best scored, right? [Pedro agrees] The items... 10, 9... were the best scored, so they have a weight of 3. They have relevance of $3 \ldots$ or another value we want to give to it. The one with the combination 3, 2, 1, so the 0 , the 1, the 2 [were] best scored, so it has a minor relevance when it is time to choose.

Pedro: Yes. This is what I was thinking: that the relevance of each question, each item, is its weight times the number of people who voted for it.

$[\cdots]$ 
Pedro: I will add the people who voted for 7, the people who voted for 8, the people who voted for 9, the people who voted for 10; I will multiply by $3 \ldots$

Maria: You want to find the weighted mean?

Pedro: Yes! [Jussara agrees] Then, this number, I'll call it relevance...

(Video transcript).

In this excerpt, Pedro describes a weighted mean and how to calculate it in the case the group was working on. That is, he developed part of the mathematization process, which, however, did not become a model (NISS et al., 2007). Pedro ends his explanation by naming the result of the weighted mean: relevance.

After the whole group had understood the way Alberto's proposed model would be used, Aline asked a question which was directed towards defining the modelling project objective:

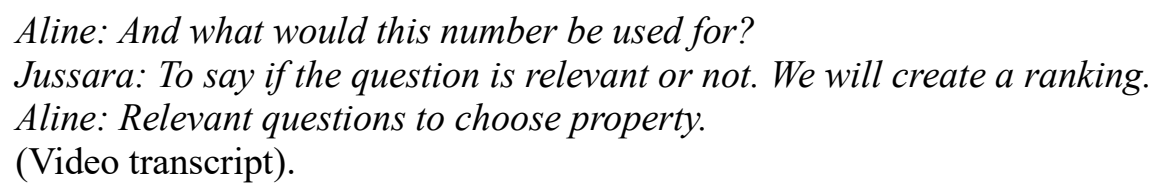

The lack of definition of an objective for the modelling project, in previous miniature cycles, also made tensions appear in the subjects' actions in the third miniature cycle. And this tension is directly connected to the one made explicit by Pedro. The tensions, then, led to changes, both in the mathematization process and in the modelling project objective, which, in its third version, was "to create a ranking of the relevant questions when choosing property".

At the end of this meeting, Maria was responsible for making the calculations according to what was idealized by the group. In order to formalize some details, Maria sent an e-mail to all participants, updating them concerning the calculations. In response to this email, Jussara pondered about the model and asked the other members their opinion:

Maria, remember my proposal, considering question by question instead of groups of answers, to calculate the weighted mean? What does the group think of doing it this way?

(Message sent by Jussara to the group on April 25th, 2013).

Some doubts appeared and Jussara provided more details:

The alternative $n$ will carry a weight of $n$, for each $n=0,1, \ldots 10$. It is a way to assess the degree of relevance for the factor the question contemplates. If many people answered 10, it is because the factor the question refers to is indeed relevant when choosing a house. Thus, the degree of relevance of question 1 would be like this (considering the data you sent): $R(1)=(0 \times 5+1 \times 1+2 \times 3+3 \times 2+4 \times 2+5 \times 30+6 \times 8+7 \times 18+8 \times 32+9 \times 10+10 \times 49) / 55=21.47$ Was that what you proposed, Pedro and Aline? (Message sent by Jussara to the group on April 30th, 2013).

Pedro's response was this:

What I thought about during the meeting is exactly what Jussara posted. I believe this treatment helps make the data 'lighter'; what I mean is, instead of looking at a bar chart with 'too much information' (poetic license), we compact all this information in a few numbers, then we can compare the relevance of a question in relation to another immediately, which is not so easy 
with bar charts with many items, in principle. Concerning the division in groups (G1, G2, and G3), I think it only helped us realize which alternatives were more relevant.

(Message sent by Pedro to the group on May 3rd, 2013).

After this debate via e-mail, Maria synthesized a model constructed to answer the third version of the modelling project objective:

$$
R(n)=\frac{p_{0} \cdot x_{0}+p_{1} \cdot x_{1}+p_{2} \cdot x_{2}+\cdots+p_{10} \cdot x_{10}}{p_{0}+p_{1}+p_{2}+\cdots+p_{10}}=\frac{\sum_{i=0}^{10} p_{i} \cdot x_{i}}{\sum_{i=0}^{10} p_{i}}(\text { Model 3) }
$$

In the model, $R(n)$ is the degree of relevance of the item $n$, for $n=1,2, \ldots, 19 ; p_{i}=i$ is the weight of each alternative, for $i=1,2, \ldots, 10$, which was equal to each of the degrees of importance that could be attributed to the item $n$ in the questionnaire; and $x_{i}$ is the number of people who chose the alternative $i$ in question $n$.

Next, we present the actions of the activity system subjects in the third miniature cycle. In this miniature cycle, two tensions arose among these actions, causing changes in the flow of actions.

- classifying the items in groups, as in the second miniature cycle;

- First tension: Pedro stated that the classification established in the second miniature cycle omitted important information and that it was necessary to refine the classification;

- presenting arguments and examples to support Pedro's statement;

- Second tension: Aline stated that the objective of the modelling project should be defined and explained to all;

- searching for ways to solve the problems found;

- consulting the group's notes and the field notes;

- reinterpreting and re-elaboration of Model 1, originating Model 3;

- elaboration of a new version of the modelling project object;

- realization of calculus following the new strategies agreed and according to Model 3;

- assessing the new strategy in comparison to the previous one.

Because of these actions, the activity system subjects elaborated a third version of the modelling project objective: Establishing a ranking of factors that might influence the choice when purchasing property. The group actions were oriented towards this third version of the objective and we consider it a new refinement of the activity system object.

With Jussara's initiative to connect the two mathematization processes from previous miniature cycles and Pedro's actions to move this process further, the activity system subjects made a connection between Models 1 and 2, creating Model 3. Thus, we consider Model 3 as a 
new version of the activity system outcome.

The mathematical elements present in the third miniature cycle were the same used in Models 1 and 2, but in a way that some helped refine the others. This prompted the elaboration of a mathematical formula (Model 3), in which all the variables and parameters had a meaning in the context of the real-world situation ${ }^{7}$. In the third miniature cycle, while dealing with tensions made explicit in the activity system, the group was able to make more conclusive developments towards the mathematization process and the definition of the modelling project objective, which leads us to see that the mathematization process happened concurrently with the delimitation of the modelling project objective.

\section{Discussion and final remarks}

Having an open modelling project as starting point, in which the students chose the theme to be investigated, we aimed to understand how mathematization was realized by the activity system subjects. At first, the group knew we were doing mathematical modelling and, therefore, we should use mathematics to approach the real-world situation (NISS et al., 2007). What we did not know was how mathematization would happen in this project. The students Alberto (first miniature cycle) and Pedro (second miniature cycle) were the ones taking the initiative of starting mathematization; however, they did it in a descriptive way, using mathematical terminology (weight, weighted mean, comparing, classifying into patterns, etc.), but without mathematical language or formulas. Researchers' intervention was needed in order to translate mathematical ideas from colloquial language to mathematical language. So, although students normally have difficulties in the mathematization process (SCHAAP et al., 2011; SOL et al., 2011), it seems that the difficulties were in the use of mathematical language, and not in the insertion of mathematical ideas.

The mathematization process described in the first and second miniature cycles happened independently. From the tensions during the third miniature cycle, made explicit by the student Pedro's questions, it was possible to connect the two previous miniature cycles and move the project towards conclusion. These tensions happened concurrently with the researcher Aline's questions - thus making explicit tensions - about the definition of an objective for the modelling project. Considering the three miniature cycles in a timeline, we can perceive the

\footnotetext{
${ }^{7}$ After the empirical part of the research, Maria observed that the choice of weights in Model 3 was inadequate, and proposed an inversion. However, since these calculations were not made with the participation of the students, we will not consider them in this paper.
} 
historicity of the activity system leading the group to face tensions which appeared during modelling project. Then, in a smaller scale, there were expansive transformations in the activity system by means of "construction and resolution of successively evolving [tensions]" (ENGESTRÖM; SANNINO, 2010, p. 7).

Because we interpreted the mathematization process as a set of actions oriented to the activity system object, and the modelling project objective as the object of the activity itself (see analysis in 5.1), we can conclude that the mathematization process took place concurrently with the delimitation of the modelling project objective. The dialectical relation (ENGESTRÖM, 2001) between the subjects' actions and the activity object helps us to understand the advances and setbacks in the subjects' actions, permeated by tensions.

The students needed the researchers' help during the mathematization process, since they had little familiarity with modelling projects. Furthermore, literature points out the students' difficulties in the mathematization process (SCHAAP et al., 2011; SOL et al., 2011) in modelling activities and, therefore, what happened here is not new.

What is different in this research is the complete openness of the project, as it is common in the Brazilian tradition of modelling in mathematical education (ARAÚJO, 2010). Such openness includes the lack of a sense of direction (MAAß, 2007) in the development and the lack of definition a priori of questions to guide the students (STILLMAN et al., 2015). CHAT proved to be appropriate to organize a set of actions that, at first, seemed disorganized, but that were oriented to the modelling project objective.

To conclude, the main contribution of this paper is highlighting that, given all the openness of the modelling project, the students were autonomous when starting the mathematization process, through colloquial language. This shows that students had a global perspective of the project, different from what Sol et al. (2011) stated - perhaps because they saw themselves as (co)responsible for the project being developed and not as a group of students working on a school task. Furthermore, the detailed description of the mathematization process, making explicit advances, setbacks, tensions, etc., in a dialectic relationship with the delimitation of the modelling project objective, is a new way of looking at this process, which was made possible by the approach from a different theoretical framework.

\section{Acknowledgments}

The research reported in this paper was developed with the support of the Conselho Nacional de Desenvolvimento Científico e Tecnológico (CNPq, process n. 473850/2011-7) and 
the Fundação de Amparo à Pesquisa do Estado de Minas Gerais (FAPEMIG, process n. PPM 00235/13). We would like to thank the members of the Cultural Historical Activity Theory in Educational Research (CHATER), from the Faculdade de Educação at UFMG, for criticism and suggestions to previous versions of this paper.

\section{References}

ADLER, P. A.; ADLER, P. Observational techniques. In: DENZIN, N. K.; LINCOLN, Y. S. (ed.). Handbook of qualitative research. Thousand Oaks: Sage Publications, 1994. p. 377-392.

ALMEIDA, L. W.; BRITO, D. S. Atividades de modelagem matemática: que sentido os alunos podem lhe atribuir? Ciência \& Educação, Bauru, v. 11, n. 3, p. 483-498, set./dez. 2005.

ALMEIDA, L. W.; SILVA, K. P.; VERTUAN, R. E. Modelagem matemática na educação básica. São Paulo: Editora Contexto, 2012.

ANTONIUS, S.; HAINES, C.; JENSEN, T. H.; NISS, M.; BURKHARDT, H. Classroom activities and the teacher. In: BLUM, W.; GALBRAITH, P. L.; HENN, H. W.; NISS, M. (ed.). Modelling and Applications in Mathematics Education. Boston: Springer, 2007. p. 295-308.

ARAÚJO, J. L. Brazilian research on modelling in mathematics education. ZDM - The International Journal on Mathematics Education, Eggenstein-Leopoldshafen, v. 42, n. 3-4, p. 337-348, jun. 2010.

. Toward a framework for a dialectical relationship between pedagogical practice and research. In: STILLMAN, G.; BROWN, J. (ed.). Lines of inquiry in mathematical modelling research in education. Chennai: Springer International Publishing, 2019. p. 21-36.

BLUM, W.; LEIß, D. How do students and teachers deal with modelling problems? In: HAINES, C.; GALBRAITH, P.; BLUM, W.; KHAN, S. (ed.). Mathematical modelling: education, engineering, and economics. Chichester: Horwood Publishing Limited, 2007. p. 222-231.

BLUM, W.; NISS, M. Applied mathematical problem solving, modelling, applications, and links to other subjects - State, trends, and issues in mathematics instructions. Educational Studies in Mathematics, Dordrecht, v. 22, p. 37-68, feb. 1991.

CARREIRA, S.; BAIOA, A. M. Students' modelling routes in the context of object manipulation and experimentation in mathematics. In: KAISER, G.; BLUM, W.; BORROMEO FERRI, R.;

STILLMAN, G. (ed.). Trends in teaching and learning of mathematical modelling. New York: Springer, 2011. p. 211-220.

DAVID, M. M.; TOMAZ, V. S. Aprendizagens expansivas reveladas pela pesquisa sobre atividade matemática na sala de aula. Bolema, Rio Claro, v. 29, n. 53, p. 1287-1308, dec. 2015.

DAVID, M. M.; TOMAZ, V. S.; FERREIRA, M. C. C. How visual representations participate in algebra classes' mathematical activity. ZDM - The International Journal on Mathematics Education, Eggenstein-Leopoldshafen, v. 46, n. 1, p. 95-107, feb. 2014.

ENGESTRÖM, Y. Innovative learning in work teams: analysing cycles of knowledge creation in practice. In: ENGESTRÖM, Y.; MIETTINEN, R.; PUNAMÄKI, R.-L. (ed.). Perspectives on activity theory. Cambridge: Cambridge University Press, 1999. p. 377-404.

. Expansive learning at work: toward an activity theoretical reconceptualization. Journal of 
Education and Work, London, v. 14, n. 1, p. 133-156, jan. 2001.

ENGESTRÖM, Y.; SANNINO, A. Studies of expansive learning: Foundations, findings, and future challenges. Educational Research Review, Amsterdam, v. 5, n. 1 p. 1-24, jan. 2010.

FOOT, K. Pursuing an evolving object: a case study in object formation and identification. Mind, culture, and activity, Abingdon, v. 9, n. 2, p. 132-149, dez. 2002.

GALLEGUILLOS, J.; BORBA, M. C. Expansive movements in the development of mathematical modeling: analysis from an activity theory perspective. ZDM - The International Journal on Mathematics Education, Eggenstein-Leopoldshafen, v. 50, n. 1-2, p. 129-142, dec. 2017.

GOOGLE DRIVE. In: WIKIPÉDIA: a enciclopédia livre. [Flórida: Wikimedia Foundation, 2015]. Available at: https://pt.wikipedia.org/wiki/Google_Drive. Accessed in: 4 mar. 2015.

MAAß, K. Modelling in class: what do we want the students to learn? In: HAINES, C.; GALBRAITH, P.; BLUM, W.; KHAN, S. (ed.). Mathematical modelling: education, engineering, and economics. Chichester: Horwood Publishing Limited, 2007. p. 63-78

NISS, M.; BLUM, W.; GALBRAITH, P. Introduction. In: BLUM, W.; GALBRAITH, P. L.; HENN, H.-W.; NISS, M. (ed.). Modelling and applications in mathematics education. New York: Springer, 2007. p. 3-44.

POSADA-BALVIN, F. A.; BORBA, M. C. Práticas algébricas no contexto de projetos pedagógicos de modelagem. Bolema, Rio Claro, v. 33, n. 63, p. 45-66, abr. 2019.

SANNINO, A.; DANIELS, H.; GUTIÉRREZ, K. D. Activity theory between historical engagement and future-making practice. In: SANNINO, A.; DANIELS, H.; GUTIÉRREZ, K. D. (ed.). Learning and expanding with Activity Theory. Cambridge: Cambridge University Press, 2009. p. 1-15.

SCHAAP, S.; VOS, P.; GOEDHART, M. Students overcoming blockages while building a mathematical model: exploring a framework. In: KAISER, G.; BLUM, W.; BORROMEO FERRI, R.; STILLMAN, G. (ed.). Trends in teaching and learning of mathematical modelling. New York: Springer, 2011. p. 137-146.

SOL, M.; GIMÉNEZ, J.; ROSICH, N. Project modelling routes in 12-16-year-old pupils. In: KAISER, G.; BLUM, W.; BORROMEO FERRI, R.; STILLMAN, G. (ed.). Trends in teaching and learning of mathematical modelling. New York: Springer, 2011. p. 231-240.

STILLMAN, G. A.; BROWN, J. P.; GEIGER, V. Facilitating mathematisation in modelling by beginning modellers in secondary school. In: STILLMAN, G. A.; BLUM, W.; BIEMBENGUT, S. (ed.). Mathematical modelling in education research and practice: cultural, social, and cognitive influences. New York: Springer, 2015. p. 93-104.

WAKE, G. Making sense of and with mathematics: the interface between academic mathematics and mathematics in practice. Educational Studies in Mathematics, Dordrecht, v. 86, p. 271-290, jun. 2014.

. Mathematics, modelling, and students in transition. Teaching Mathematics and its Applications, v. 35, n. 3, p. 172-186, sep. 2016. 


\section{Appendix: summary of the questionnaire}

The questionnaire used in the research was made of two parts:

Part 1: Presents a number of questions concerning personal data of the interviewee (e.g., name, date of birth, education level, etc.)

Part 2: The interviewee was asked to evaluate a series of items according to the level of importance, to them, when purchasing property (real estate). The instructions were the following:

Imagine you intend to purchase property and need to choose between the options available at the moment. A real estate company you are consulting has a programme which can help you. It presents a list of items to each you should attribute a single value, from 0 to 10 , according to the level of importance you give to each item: associate 0 to the item(s) with no importance and 10 to the item(s) of extreme importance to you. Below is the list of items.

NB: N/A means 'not applicable'. Use it only if the situation presented is not applicable to your reality. In case the item is totally irrelevant, attribute this item the value 0 .

1. Distance from workplace;

2. Distance from the city centre;

3. Distance from school and other routine activities in the family;

4. Distance from the commercial area (supermarkets, pharmacies, etc.);

5. Relief of the area;

6. Proximity to water streams, lakes, green areas;

7. Proximity to industrial areas;

8. Proximity to leisure areas: shopping centres, museums, theatre, stadiums, tourist attractions;

9. Proximity to bars and nightclubs;

10. Proximity to hospitals;

11. Easy access to public transport;

12. Level of the service in public transport in the area (schedule, number of lines and vehicles, comfort);

13. Proximity to relatives' houses;

14. Interest in the property (your feelings towards it);

15. History of the property (in case of a family property or even a relevant past to you);

16. Financial value of the property;

17. Easy payment methods for the acquisition of the property (available loans, longer financing options, etc.);

18. Empathy with the neighbours;

19. Availability of telematics services (cable or satellite TV, broadband internet, landline telephones, mobile phones, VoIP phone, digital TV, etc.). 